\title{
MORFOMETRI PERUBAHAN GARIS PANTAI KURA-KURA DESA KARIMUNTING MENGGUNAKAN CITRA TIME SERIES DAN FAKTOR PENGARUHNYA
}

\author{
Agus Sugiarto ${ }^{*}$ \\ ${ }^{1}$ Program Studi Pendidikan Geografi, Fakultas Keguruan dan Ilmu Pendidikan, Universitas Tanjungpura,Pontianak, Indonesia. \\ *Email Koresponden: agusnepster@fkip.untan.ac.id
}

Diterima: 16-05-2021, Revisi: 28-05-2021, Disetujui: 11-06-2021

(C)2021 Program Studi Pendidikan Geografi, FISE, Universitas Hamzanwadi

\begin{abstract}
Abstrak Akselerasi perubahan garis pantai akibat abrasi yang terjadi di pantai Kura-kura Desa Karimunting dari waktu ke waktu sangat dirasakan oleh masyarakat stempat. Diperlukan kajian untuk mendeskripsikan fenomena tersebut secara keruangan sehingga dapat dijadikan acuan dalam mencari solusi atas permasalahan yang terjadi. Tujuan penelitian ini adalah: 1) mengukur perubahan garis Pantai Kura-Kura Desa Karimunting; 2) untuk mengkaji bagaimana faktor akselerasi abrasi Pantai Kura-Kura Desa Karimunting dari aspek fisik; dan 3) untuk mengkaji bagaimana faktor akselerasi abrasi Pantai Kura-Kura Desa Karimunting dari aspek sosial. Metode penelitian ini adalah deskriptif kualitatif dengan teknik analisis data proses keruangan dengan overlay citra time series tahun 2008 dan 2018. Teknik pengumpulan data yang digunakan dalam penelitian ini adalah observasi, dokumentasi dan wawancara. Hasil penelitian menunjukkan bahwa: 1) perubahan garis pantai Kura-kura Desa Karimunting selama 12 tahun sepanjang 28,4 meter atau 2,37 meter pertahun; 2) faktor fisik yang mempengaruhi akselerasi abrasi Pantai Kura-kura yaitu: iklim dimana pergerakan angin yang mempengaruhi pergerakan arus laut dan topografi pantai yang memotong pergerakan arus laut dan minimnya vegetasi penutup lahan; dan 3) aspek sosial yang memberikan akselerasi abrasi pantai Kura-kura desa Karimunting adalah aktifitas sosial ekonomi yang tidak memperhatikan kearifan ekologis.
\end{abstract}

Kata kunci: morfometri, perubahan garis pantai, pantai kura-kura, time series

\begin{abstract}
The acceleration of shoreline changes due to abrasion that occurs on Kura-kura beach in Karimunting Village from time to time is deeply felt by the local community. A study is needed to describe this phenomenon spatially so that it can be used as a reference in finding solutions to the problems that occur. The aims of this study were: 1) measuring changes in the coastline of the Kura-Kura Beach in Karimunting Village; 2) to examine how the abrasion acceleration factor of Kura-Kura Beach in Karimunting Village is from the physical aspect; and 3) to examine how the abrasion acceleration factor of Kura-Kura Beach in Karimunting Village is from the social aspect. This research method is descriptive qualitative with spatial process data analysis techniques with time series image overlays in 2008 and 2018. The data collection techniques used in this study are observation, documentation and interviews. The results showed that: 1) the change in the coastline of the Turtles in Karimunting Village for 12 years was 28.4 meters or 2.37 meters per year; 2) physical factors that affect the acceleration of the abrasion of Turtle Beach, namely: a climate where wind movements affect the movement of ocean currents and coastal topography that cuts through the movement of ocean currents and the lack of vegetation cover; and 3) the social aspect that accelerates the abrasion of the turtle beach in Karimunting village is a socio-economic activity that does not pay attention to ecological wisdom.
\end{abstract}

Keywords: morphometry, shoreline changes, kura-kura beach, time series

\section{PENDAHULUAN}

Indonesia dikenal sebagai negara maritim dengan dua pertiga dari keseluruhan wilayahnya adalah perairan. Luas wilayah perairan Indonesia mencapai 5,8 Juta $\mathrm{km}^{2}$ atau sekitar $75 \%$ dari total luas Indonesia (Muhamad, 2016). Dilihat dari aspek fisik secara umum Indonesia merupakan negara kepulauan (archipelagic state), dengan jumlah pulau 17.508 pulau baik besar maupun kecil (Purwaka, 2015). Konsekuensi dari jumlah pulau yang mencapai 17.508 tersebut maka, Indonesia mempunyai garis pantai terpanjang nomer dua di dunia setelah Kanada yang mencapai 202.800 kilometer yaitu mencapai 
99.093 kilometer (Arifin, Awaluddin, \& Amarrohman, 2020). Luas wilayah daratan Indonesia secara keseluruhan mencapai 1.919.443 $\mathrm{km}^{2}$ (Saksono, 2013).

Sebagai negara yang mempunyai garis pantai terpanjang nomer dua setelah Kanada, Indonesia mempunyai potensi sumber daya laut yang besar baik sumberdaya hayati maupun sumberdaya nonhayati (Hoek et al., 2015). Posisi Indonesia yang terletak di garis khatulistiwa yang merupakan pertemuan arus panas dan dingin, menyebabkan sumberdaya hayati kelautan Indonesia begitu beraneka ragam (Sukamto, 2017). Potensi sumber daya kelautan dan kemaritiman tidak hanya berkaitan dengan badan laut tetapi juga mencakup wilayah pesisir dan pantai. Pesisir adalah wilayah yang membentuk batasan antara daratan dan laut dan dapat memanjang kearah darat dan kearah laut dengan luas yang beragam, tergantung pada keadaan topografi, tujuan dan kebutuhan program khusus (Sara, 2014). Wlayah Pesisir (Coastal area) mempunyai potensi yang sangat besar dan merupakan aset yang sangat menjanjikan untuk menunjang perekonomian di masa depan jika dikelola dengan baik (Putri \& Citra, 2018). Potensi bahari yang sangat besar saat ini menjadi perhatian yang sangat besar pemerintah yang dibuktikan dengan adanya nomenklatur kementrian perikanan dan kelautan di bawah koordinator kementrian bidang kemaritiman.

Laut Indonesia mempunyai potensi yang sangat luar biasa baik dari aspek ekonomi yaitu sebagai tambatan hidup masyarakat Indonesia yang sebagian besar berprofesi sebagai nelayan dan petani. Selain itu wilayah pesisir yang mengikuti panjangnya garis pantai laut Indonesia juga memiliki potensi yang sama dalam hal potensi wisata bahari. Wisata bahari adalah wisata yang memanfaatkan daya tarik lingkungan pesisir (coastal area) yang berupa rekreasi pantai, kegiatan berenang, berjemur, snorkeling, berselancar, menyelam, berlayar, memancing, fisiografi bawah air dan sejenisnya (Yani et al., 2018). Ribuan area pantai dengan kekhasan geografis dengan potensi yang berbeda-beda menjadi daya tarik kunjungan wisatawan baik domestik maupun mancanegara. Potensi yang luar biasa ini penting untuk ditumbuhkembangkan guna mendongkrak pembangunan Indonesia yang lebih maju.

Provinsi Kalimantan Barat merupakan 1 dari 34 provinsi di Indonesia yang mempunyai potensi wilayah pantai cukup besar di sisi barat. Propinsi Kalimantan Barat mempunyai garis pantai (Soreline) dengan panjang mencapai 497 mil atau sekitar 799 kilometer diukur menggunakan Ruler Tool pada aplikasi Google Earth, belum lagi wilayah garis pantai di pulau-pulau kecil yang ada di sebelah barat Provinsi Kalimatan Barat. Salah satu pantai yang mempunyai keunikan tersendiri dibandingkan dengan pantai-pantai yang lain terdapat di Provinsi Kalimantan Barat adalah Pantai Kura-Kura yang secara administratif masuk di Desa Karimunting, Kecamatan Sungai Raya Kepulauan, Kabupaten Bengkayang Kalimantan Barat. Satu permasalahan yang terjadi di Pantai Kura-Kura adalah abrasi pantai yang begitu masif. Bukti adanya proses abrasi pantai yang masif adalah adanya batu-batu besar yang bertebaran tersingkap disekitar pantai utamanya di kaki perbukitan yang ada disebelah selatan kawasan pantai. Singkapan batu-batuan yang ada di kawasan pantai ini adalah bukti awal dari proses abrasi yang terjadi dikawasan pantai ini.

Beberapa penelitian yang mengangkat tema pantai dan coastal area banyak memberikan kajian terkait dengan fluktuasi perubahan garis pantai. Fluktuasi perubahan garis pantai selalu terjadi dan sangat bervariatif di setiap lokasi. Setiap pantai mempunyai deferensiasi/karakteristik tersendiri baik dari aspek fisik maupun aspek sosial lingkungan pantai. Perubahan garis pantai merupakan proses yang terjadi akibat adanya pengaruh dari kondisi pantai dalam mencapai keseimbangan terhadap dampak yang terjadi dari faktor alami dan kegiatan manusia (Nurjaya \& Atmadipoera, 2020). Sejalan dengan Penelitian ini, penelitian dari Raihansyah, Setiawan, \& Rizwan, (2016) menyatakan bahwa perubahan garis pantai berlangsung lambat, tetapi jika faktor akselerasi baik alami maupun non-alami terdapat di lingkungan pantai tersebut maka dimungkinkan perubahan tersebut terjadi dengan cepat.

Penelitian lain menunjukan perubahan garis pantai di kawasan pesisir Kabupaten Tuban bagian barat dalam kurun 1994-2003 menunjukan perubahan garis pantai didominasi oleh kemajuan garis pantai (Richard \& Sunarto, 2015). Penelitian Nurjaya \& Atmadipoera, 2020 serta penelitian dari Raihansyah, Setiawan, \& Rizwan, (2016) dilakukan pada tempat dan karakteristik pantai yang berbeda, namun menunjukan hasil yang relatif sejalan yaitu bahwa faktor alami dan non-alami (kegiatan manusia) banyak memberikan pengaruh yang besar terhadap perubahan garis pantai. Lain halnya penelitian yang dilakukan Richard \& Sunarto (2015) yang menunjukan bahwa fluktuasi perubahan garis pantai bisa 
terjadi secara maju dan mundur. Pada penelitian ini, tentu pantai sebagai lokasi penelitian mempunyai karakteristik yang berbeda dengan penelitian-penelitian sebelumnya, baik dari aspek fisik maupun aspek sosialnya. Karakteristik pantai yang berbeda menjadi dasar peneliti untuk menfokuskan bagaimana perubahan garis pantai dan pengaruh aspek fisik dan sosial dalam memberikan akselerasi terhadap perubahan garis pantai Kura-kura Desa Karimunting tersebut. Kajian ini diharapkan dapat dijadikan pijakan dan edukasi bagi masyarakat akan pentingnya menjaga keseimbangan ekosistem pantai.

\section{METODE PENELITIAN}

Metode yang digunakan dalam penelitian ini adalah deskriptif kualitatif dengan pendekatan deskriptif keruangan. Analisa data yang digunakan dalam penelitian ini adalah dengan pemetaan atau mapping area dengan teknik time series. Time series adalah kumpulan dari pengamatan yang dilakukan secara berurutan melalui contoh waktu terjadi dalam berbagai bidang, mulai dari ekonomi hingga rekayasa, dan metode analisis time series merupakan area penting dari statistik (Saleh, 2014). Teknik time series penekanannya yaitu pengamatan yang dilakukan secara berurutan, dalam hal ini yaitu berdasarkan dengan urutan waktu. Teknik time series dalam penelitian ini digunakan untuk mendapatkan data perubahan garis pantai dengan urutan waktu dari tahun 2008 dan tahun 2018. Tahapan-tahapan dalam teknik time series ini yaitu: 1) mencapture secara berurutan citra tahun 2008 dan tahun 2018 dari aplikasi Google Earth; 2) delineasi pada masing-masing citra yang telah di-capture menggunakan software Arc GIS 10.4 dengan terlebih dahulu melakukan georeference; 3) melakukan overlay; 4) melakukan calculate geometry perubahan garis pantai pada beberapa titik yang ditentukan.

Untuk menganalisis bagaimana pengaruh aspek fisik dan aspek sosial terhadap perubahan garis pantai yang telah didapatkan maka diperlukan data pendukung yaitu: 1) Peta Arus Laut; 2) Topografi; 3) Penggunaan Lahan; 4) Geologi; 5) data aktivitas sosial ekonomi sepempat. Untuk melihat lebih jelas terkait dengan teknik analisa data pada penelitian ini dapat diamati pada diagram berikut ini

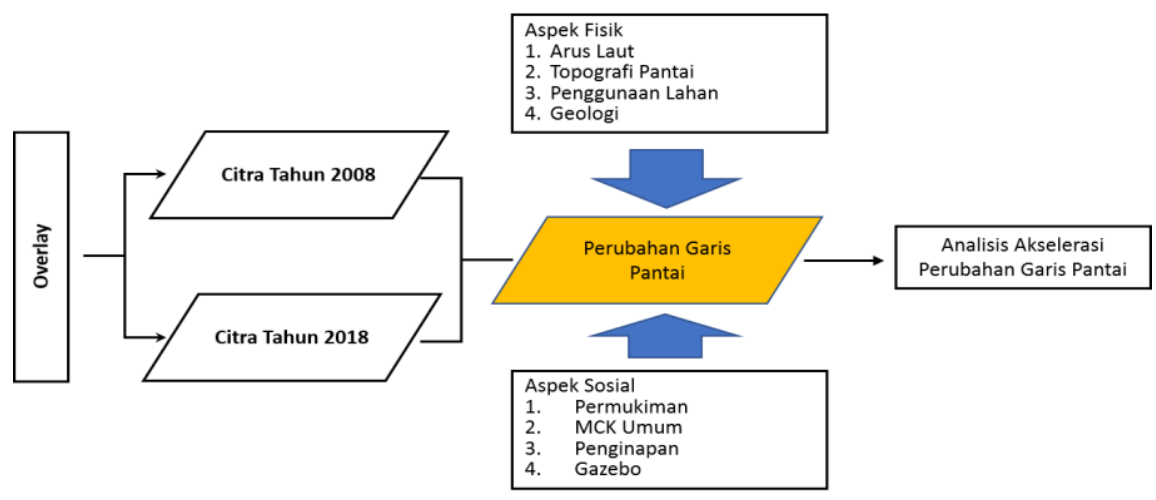

Gambar 1. Diagram Alur Teknik Analisis Data

(Sumber: Peneliti, 2018)

Tahapan-tahapan dalam penelitian ini meliputi: 1) tahap persiapan (studi literature, pengumpulan data peta RBI lembar Singkawang, peta geologi untuk lembar Singkawang, citra time series dari Google Earth, peta arus laut, dan penggunaan lahan; 2) tahap pelaksanaan (mapping, pengolahan data \& calculate geometry, observasi lapangan, analisis data); 3) tahap pelaporan hasil penelitian.

\section{TEMUAN DAN PEMBAHASAN}

\section{Deskripsi Lokasi Penelitian}

Desa Karimunting adalah desa yang berlokasi di pesisir barat Kalimantan Barat, tepatnya $110 \mathrm{~km}$ dari Pontianak, di Kecamatan Sungai Raya Kepulauan, Bengkayang dengan titik koordinat $0^{\circ} 45^{\prime} 12,85^{\prime \prime}$ LU dan 10853'08,64" BT dengan ketinggian 4 meter di bawah permukaan laut. Desa ini dihuni sekitar kurang lebih 10 ribu jiwa dari berbagai etnis antara lain: Suku Melayu, Tionghua, Madura, Bugis, Dayak, Buton, dan lain-lain dengan agama anutan antara lain Islam, Katolik, Budha, Konghuchu, dan Protestan. Mata pencaharian masyarakat di Desa Karimunting di antaranya adalah nelayan, petani, 
pegawai negeri, dan buruh. Objek wisata yang ada di Desa Karimunting cukup banyak antara lain; Pantai Teluk Suak, Pulau Kabung, Pantai Batu Payung, Pantai Kura-Kura, dan Pantai Samudra Indah.

Desa Karimunting cukup luas sekitar 194,50 $\mathrm{km}^{2}$ yang membentang dari Pasir Panjang sampai Sungai Raya. Adapun batas-batas desa ini antara lain: 1) sebelah utara berbatasan dengan Kota Singkawang; 2) sebelah selatan berbatasan dengan Desa Sungai Raya; 3) sebelah barat berbatasan dengan Laut Natuna; 4) sebelah timur berbatasan dengan Kota Singkawang dan Kecamatan Capkala.

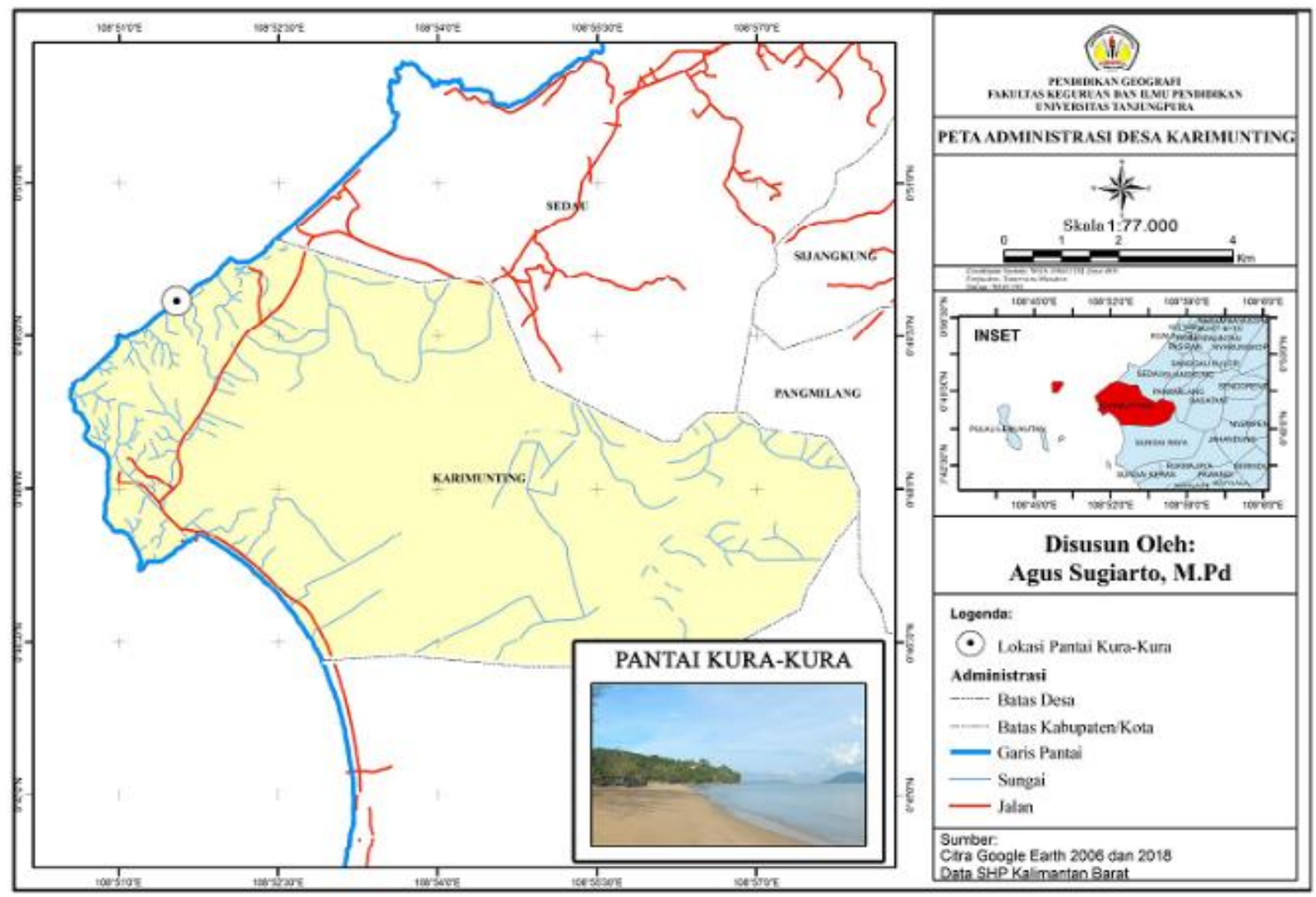

Gambar 2. Peta Administrasi Desa Karimunting

(Sumber: Olahan Data Primer, 2018)

Iklim di Desa Karimunting masih satu tipe dengan Kecamatan Sungai Raya Kepulauan yang beriklim tropis dengan suhu rata-rata berkisar antara $23{ }^{\circ} \mathrm{C}$ sampai dengan $31^{\circ} \mathrm{C}$ dengan rata-rata kelembaban udara adalah 86\% (Dinas PU, 2013). Iklim tropis di Desa Karimunting Kecamatan Sungai Raya Kepualauan termasuk klasifikasi iklim tropis basah dengan curah hujan rata-rata 3321,33 $\mathrm{mm} /$ tahun (BPS Bengkayang, 2017). Curah hujan yang tertinggi terjadi pada bulan September sampai dengan Januari dan curah hujan terendah antara bulan Juni sampai dengan Agustus. Berdasarkan Peta Ketinggian pada Gambar 6, Kecamatan Sungai Raya Kepulauan memiliki wilayah datar dan sebagian besar merupakan dataran rendah antara 50 meter s/d 100 meter di atas permukaan laut.

Berdasarkan Peta Geologi Lembar Singkawang, Kalimantan tahun 1993, Kondisi Geologi Desa Karimunting Kecamatan Sungai Raya sebagian besar di dominasi oleh formasi batuan Alluvium Deposit. Batuan aluvium adalah batuan yang terbentuk asal proses fluvial, yaitu proses yang dipengaruhi oleh aliran sungai. Formasi batuan di wilayah Desa Karimunting Kecamatan Sungai Raya ini terbagi menjadi 6 area yaitu Formasi Batuan Aluvium Deposits, Formasi Batuan Dissected Aluvium Deposits Formasi Batuan Hamisan, Formasi Batuan Alluvium Litoral Deposits dan Formasi Batuan Gunungapi Raya dan Formasi Batuan Terobosan Sintang (Sintang Intrusives). Untuk melihat lebih jelas kaitannya kondisi geologi Desa Karimunting Kecamatan Sungai Raya, Kabupaten Bengkayang maka disajikan pada Gambar 3 (Suwarna \& AGSO, 1993). 


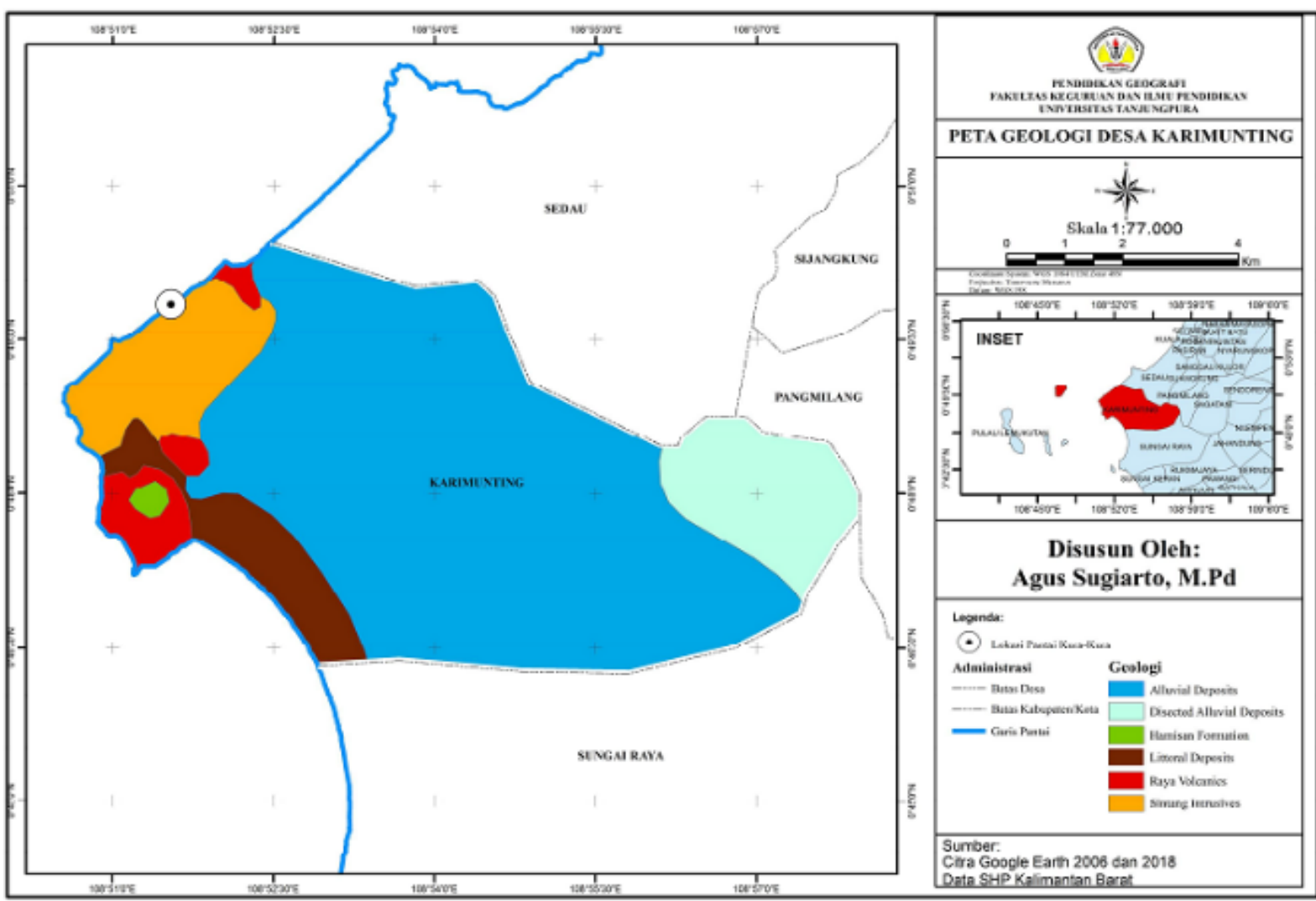

Gambar 3. Peta Geologi Desa Karimunting

(Sumber: Olahan Data Primer, 2018)

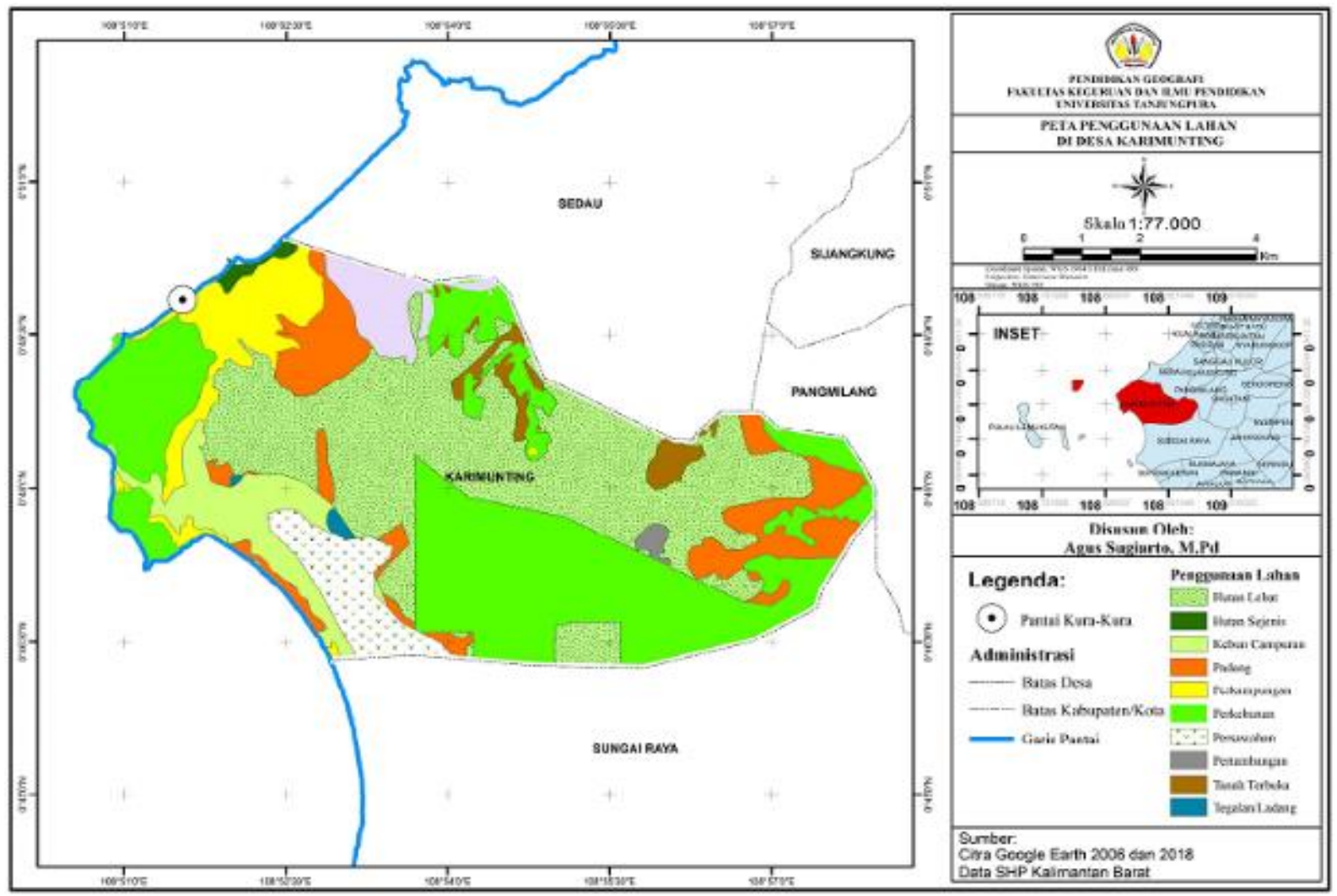

Gambar 4. Peta Penggunaan Lahan Desa Karimunting

(Sumber: Olahan Data Primer, 2018) 
Penggunaan Lahan merupakan aktivitas manusia dalam kaitannya dengan lahan, yang biasanya tidak secara langsung tampak dari citra. Penggunaan lahan telah dikaji dari beberapa sudut pandang yang berlainan, sehingga tidak ada satu definisi yang benar-benar tepat di dalam keseluruhan konteks yang berbeda. Penggunaan lahan dilihat dari sudut pandang kemampuan lahan dengan jalan mengevaluasi lahan dalam hubungannya dengan bermacam-macam karakteristik alami. Penggunaan lahan berkaitan dengan kegiatan manusia pada bidang lahan tertentu, misalnya permukiman, perkotaan dan persawahan. Penggunaan lahan juga merupakan pemanfaatan lahan dan lingkungan alam untuk memenuhi kebutuhan manusia dalam penyelenggaraan kehidupannya. Pengertian penggunaan lahan biasanya digunakan untuk mengacu pemanfaatan masa kini (present or current land use). Oleh karena aktivitas manusia di bumi bersifat dinamis, maka perhatian sering ditujukan pada perubahan penggunaan lahan baik secara kualitatif maupun kuantitatif.

Penutup lahan yang menggambarkan konstrukasi vegetasi dan buatan yang menutup permukaan lahan. Konstruksi tersebut seluruhnya tampak secara langsung dari citra penginderaan jauh. Tiga kelas data secara umum yang tercakup dalam penutup lahan: 1) struktur fisik yang dibangun oleh manusia; 2) fenomena biotik seperti vegetasi alami, tanah pertanian dan kehidupan binatang; 3) tipe pembangunan. Jadi, berdasarkan pada pengamatan penutup lahan, diharapkan untuk dapat menduga kegiatan manusia dan penggunaan lahan. Namun, ada aktivitas manusia yang tidak dihubungkan secara langsung dengan tipe penutup lahan seperti aktivitas rekreasi. Selanjutnya, pemetaan penggunaan lahan dan penutup lahan membuat beberapa keputusan bijak harus dibuat dan peta hasil tidak dapat dihindari mengandung beberapa informasi yang digeneralisasikan menurut skala dan tujuan aplikasinya (Sutanto, 1995). Peta penggunaan lahan di Desa Karimunting dapat dilihat sebagaimana ditampilkan pada Gambar 4.

\section{Morfometri Perubahan Garis Pantai Kura-kura}

Morfometri adalah suatu studi yang bersangkutan dengan variasi dan perubahan dalam bentuk (ukuran dan bentuk) dari suatu objek, meliputi pengukuran panjang dan analisis kerangka suatu objek (Sembiring, Hamdan, \& Mirwandhono, 2013). Analisis morfometrik didefinisikan sebagai sebuah kajian yang berhubungan dengan variasi dan perubahan bentuk (ukuran dan bentuk) dari organisme atau objek yang meliputi pengukuran panjang dan analisis kerangka secara kuantitatif (Taqwin et al., 2014). Berdasarkan pengukuran yang telah dilakukan dengan rentang waktu (time series) 2008 sampai 2018 didapatkan Peta Perubahan Garis Pantai Kura-Kura yang diukur pada 5 sampel pengukuran yang selanjutnya diberikan kode titik A, B, C, D dan E, di sepanjang Pantai Kura-kura dari ujung selatan sampai ke ujung utara. Pengukuran yang telah dilakukan didapatkan angka-angka perubahan garis pantai yaitu:

Tabel 1. Titik Sampel Koordinat Perubahan Garis Pantai Kura-Kura Desa Karimunting

\begin{tabular}{ccccc}
\hline \multirow{2}{*}{ No. } & Titik & \multicolumn{2}{c}{ Koordinat } & Perubahan Garis Pantai \\
\cline { 3 - 4 } & & Lintang & Bujur & \\
\hline 1 & $\mathrm{~A}$ & $0^{\circ} 49^{\prime} 32.03^{\prime \prime} \mathrm{N}$ & $108^{\circ} 51^{\prime} 6.62^{\prime \prime} \mathrm{E}$ & 14 meter \\
2 & $\mathrm{~B}$ & $0^{\circ} 49^{\prime} 40.10^{\prime \prime} \mathrm{N}$ & $108^{\circ} 51^{\prime} 17.60^{\prime \prime} \mathrm{E}$ & 24 meter \\
3 & $\mathrm{C}$ & $0^{\circ} 49^{\prime} 50.73^{\prime \prime} \mathrm{N}$ & $108^{\circ} 51^{\prime} 30.90^{\prime \prime} \mathrm{E}$ & 28 meter \\
4 & $\mathrm{D}$ & $0^{\circ} 50^{\prime} 0.52^{\prime \prime} \mathrm{N}$ & $108^{\circ} 51^{\prime} 43.76^{\prime \prime} \mathrm{E}$ & 36 meter \\
5 & $\mathrm{E}$ & $0^{\circ} 50^{\prime} 10.07^{\prime \prime} \mathrm{N}$ & $108^{\circ} 51^{\prime} 55.87^{\prime \prime} \mathrm{E}$ & 40 meter \\
\hline
\end{tabular}

Sumber: Data Primer Penelitian, 2018.

Berdasarkan lima (5) sampel pengukuran yang telah dilakukan didapatkan rata-rata perubahan garis pantai Kura-kura adalah 28,4 meter. Angka perubahan garis pantai sebesar 28,4 ini merupakan angka perubahan dengan rentang waktu selama 12 tahun. Untuk melihat lebih jelas dapat dilihat pata peta dibawah ini. 


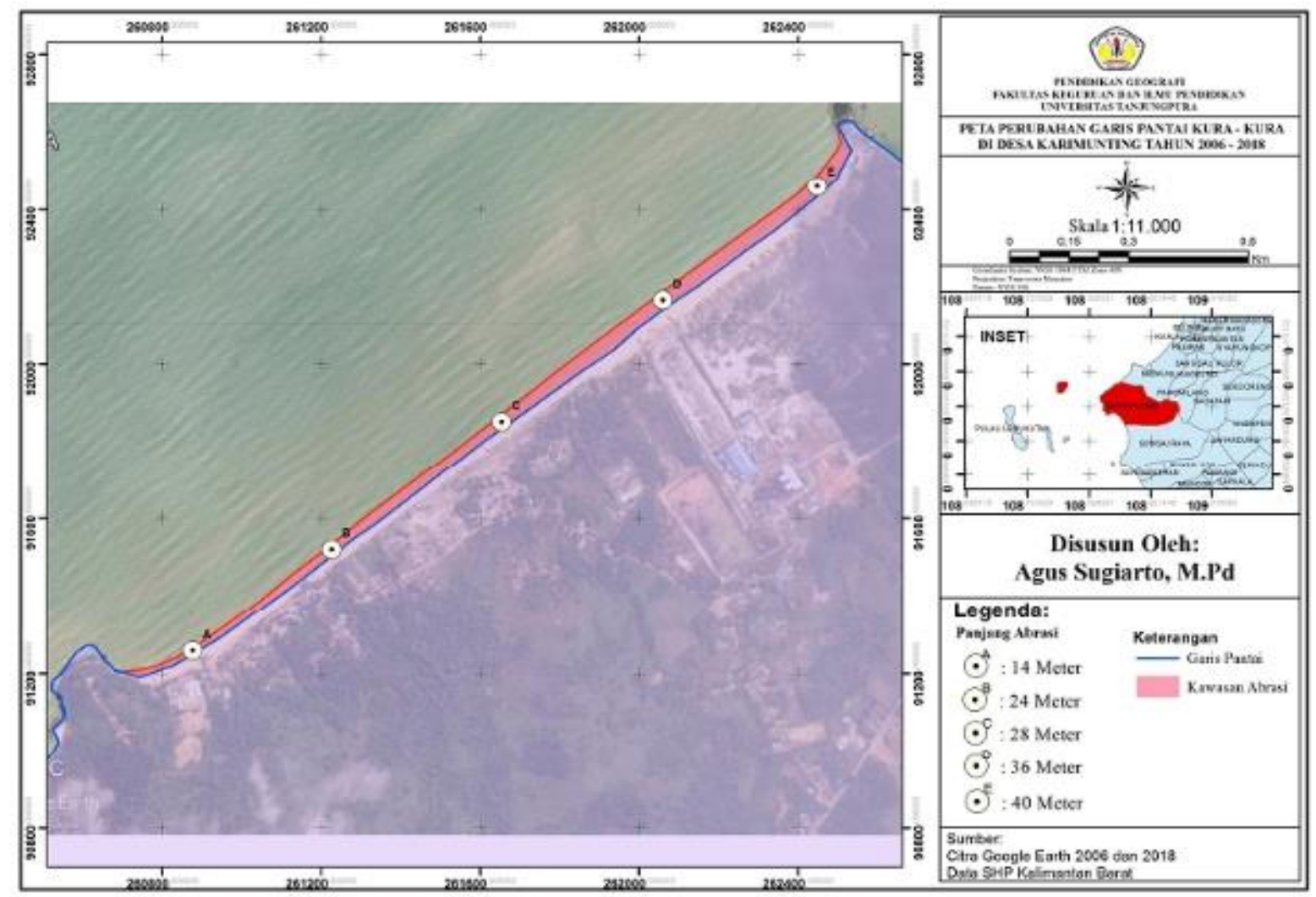

Gambar 5. Peta Perubahan Garis Pantai Kura-kura Desa Karimunting (Sumber: Olahan Data Primer, 2018)

Berdasarkan lima (5) sampel pengukuran yang telah dilakukan didapatkan rata-rata perubahan garis pantai Kura-kura adalah 28,4 meter. Angka perubahan garis pantai sebesar 28,4 ini merupakan angka perubahan dengan rentang waktu selama 12 tahun. Melihat dalam kurun waktu 12 tahun terjadi abrasi pantai sepanjang 28,4 meter sangat terlihat bahwa tingkat abrasi yang terjadi di pantai Kura-kura ini sangat masif. Sebagaimana diungkapkan oleh Damaywanti (2013) yang menyatakan bahwa abrasi merupakan pengikisan atau pengurangan daratan (pantai) akibat gelombang, arus, dan pasang surut. Kondisi kemiringan lerang yang berbeda antara sisi sebelah selatan dan utara seperti Gambar 6, juga merupakan indikator bahwa semakin menjorok kelaut maka akan semakin menghalangi arus laut, sehingga tingkat abrasinya lebih tinggi. Dilihat dari kondisi Geomorfologis terlihat banyaknya singkapan batuan. Batu-batu yang ada di pantai ini tentunya tidak muncul begitu saja tanpa adanya proses geomorfologi yang terjadi. Selain singkapan batuan, topografi kemiringan lereng adalah salah satu indikator bukti masifnya abrasi pantai yang terjadi. Untuk melihat kemiringan lereng pantai Kura-kura pada penelitian ini dilakukan dengan membuat profil ketinggian (Elevation Profile) dengan mengambil 2 (dua) garis sampel A dan B (Gambar 6).

Berdasarkan 2 sampel garis A dan B yang telah dibuat tampak bahwa kemiringan lereng A lebih curam daripada kemiringan lereng B. Kondisi Geomorfologis pantai Kura-kura meliputi bentuk lahan yang terjadi di wilayah ini. Adapun bentuk lahan yang terbentuk pada wilayah ini antara lain: 1) Bentuk lahan marin yaitu bentuk lahan yang terbentuk dari proses aktivitas kelautan seperti pasang surut air laut, gelombang, arus dan ombak; 2) Bentuk lahan asal proses aeolin yaitu bentuk lahan asal proses angin yaitu berupa proses pengikisan, pengangkutan, dan pengendapan sehingga terbentuklah bentuklahan panta berpasir; dan 3) Bentuk lahan asal proses fluvial yaitu bentuk lahan yang terbentuk asal proses air seperti aktivitas ombak atau gelombang laut sehingga menimbulkan bentuk lahan seperti tebing pantai (cliff) dan singkapan batuan atau terjadinya abrasi akibat tenaga gelombang laut. 


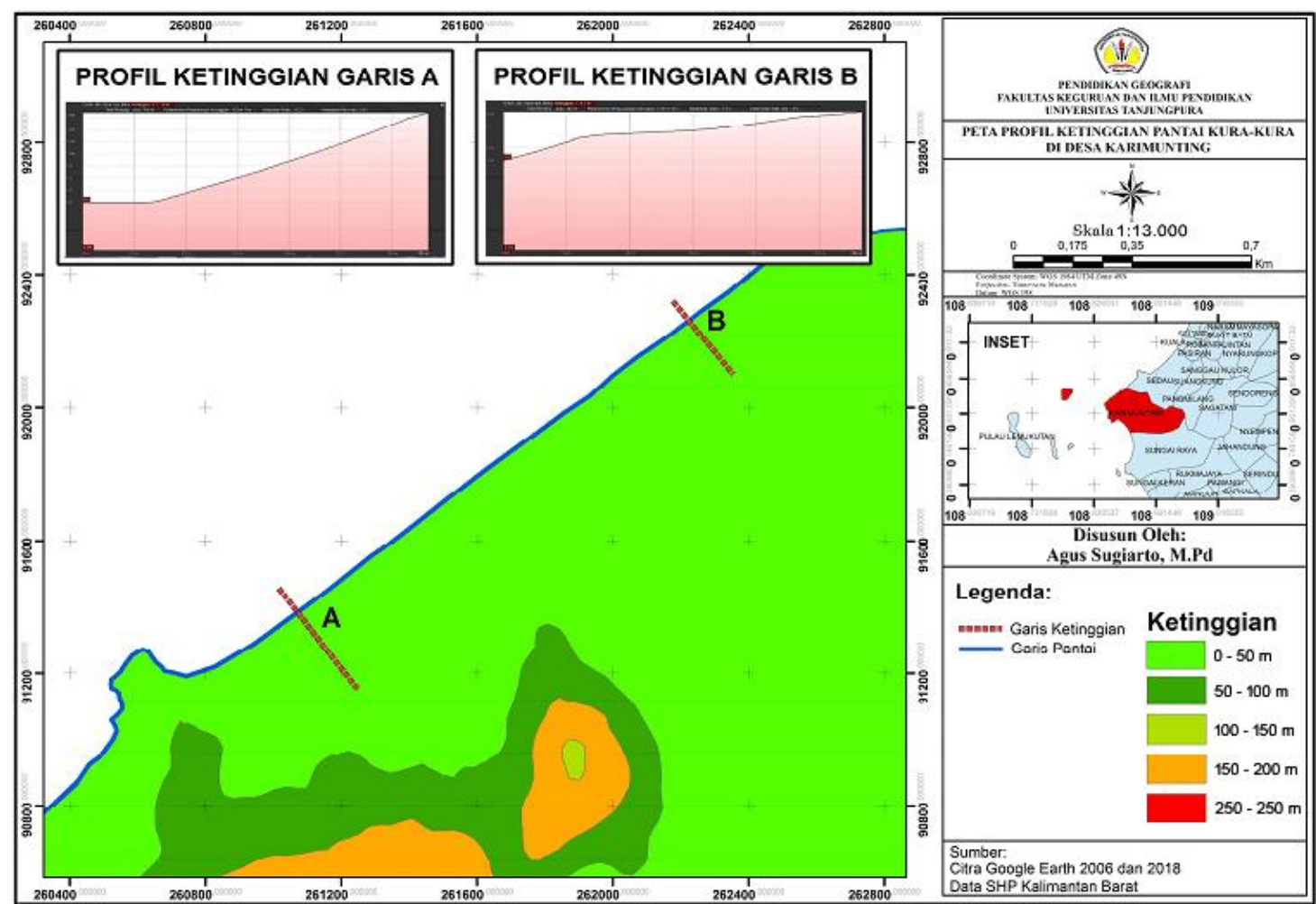

Gambar 6. Peta Profil Ketinggian Pantai Kura-kura Desa Karimunting

(Sumber: Olahan Data Primer, 2018)

\section{Aspek Fisik yang Mempengaruhi Perubahan Garis Pantai Kura-Kura Desa Karimunting}

Berdasarkan pengunaan lahan, kondisi fisik wilayah Desa Karimunting banyak didominasi hutan lebat dan perkebuman. Aktivitas permukiman banyak mendominasi daerah pesisir barat, sementara untuk kegiatan persawahan dan perladangan yang terdapat pada sisi selatan. Aktivitas pertambangan terdapat pada sisi sebelah utara.

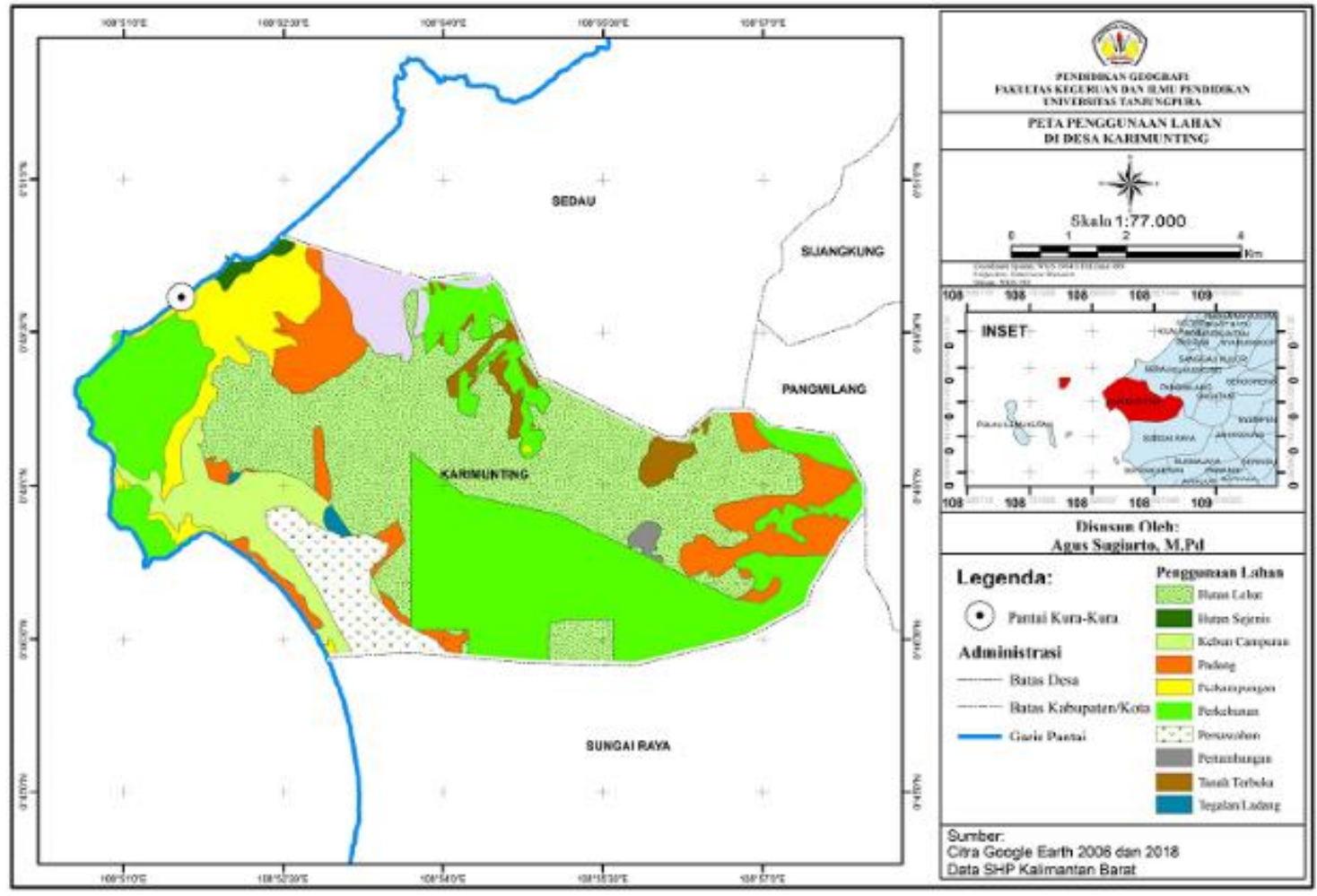

Gambar 7. Peta Penggunaan Lahan Pantai Kura-kura Desa Karimunting

(Sumber: Olahan Data Primer, 2018) 
Dengan melihat peta penggunaan lahan sebagaimana pada Gambar 7, maka dapat dideskripsikan bahwa vegetasi penutup lahan di pantai Kura-kura desa Karimunting sangat kurang. Tidak adanya akarakar pohon yang dapat menahan tebing-tebing pantai dari terpaan gelombang laut membuat tebingtebing pantai menjadi mudah untuk terabrasi oleh aktivitas air laut. Kondisi ekologis yang cukup memprihatinkan merupakan indikator penyumbang akselerasi abrasi pantai kura-kura. Kurangnya vegetasi penutup lahan di daerah pantai membuat tanah tebing pantai menjadi rentan dengan hantaman gelombang laut. Aktivitas permukiman dan bangunan-bangunan semi permanen yang mendominasi area pantai yang berhadapan langsung dengan laut menggeser fungsi kawasan yang seharusnya. Banyaknya aktivitas permukiman dan bangunan semi permanen seperti warung dan gazebo semakin mengurangi space/ruang terbuka hijau sebagai penutup lahan.

Sementara itu jika dilihat dari pergerakan arus laut yang saling bergantian karena adanya angin muson membuat akselerasi percepatan abrasi pantai. Singkapan-singkapan batuan yang terdapat di ujung Pantai Kura-kura sebelah selatan adalah sebagai bukti masifnya tingkat abrasi pantai. Sirkulasi air laut di perairan Indonesia dipengaruhi oleh sistem angin muson. Sistem angin muson ini bertiup secara tetap dengan kecepatan relatif besar, menciptakan pola arus laut yang saling bergantian dari arah utara ke selatan. Pada musim barat, pola arus permukaan perairan Indonesia memperlihatkan arus berge rak dari Laut Cina Selatan menuju Laut Jawa. Sedangkan pada saat Muson Tenggara, arah arus sepenuhnya berbalik arah menuju ke barat yang akhirnya akan menuju ke Laut Cina Selatan (Wyrtki, 1961).

Pergerakan arus laut yang saling bergantian karena adanya angin muson membuat akselerasi percepatan abrasi pantai. Singkapan-singkapan batuan yang terdapat diujung pantai kura-kura sebelah selatan adalah sebagai bukti masifnya tingkat abrasi pantai. Sirkulasi air laut di perairan Indonesia dipengaruhi oleh sistem angin muson. Oleh karena sistem angin muson ini bertiup secara tetap, walaupun kecepatan relatif tidak besar, maka akan tercipta suatu kondisi yang sangat baik untuk terjadinya suatu pola arus. Pada musim barat, pola arus permukaan perairan Indonesia memperlihatkan arus bergerak dari Laut Cina Selatan menuju Laut Jawa. Di Laut Jawa, arus kemudian bergerak ke Laut Flores hingga mencapai Laut Banda.

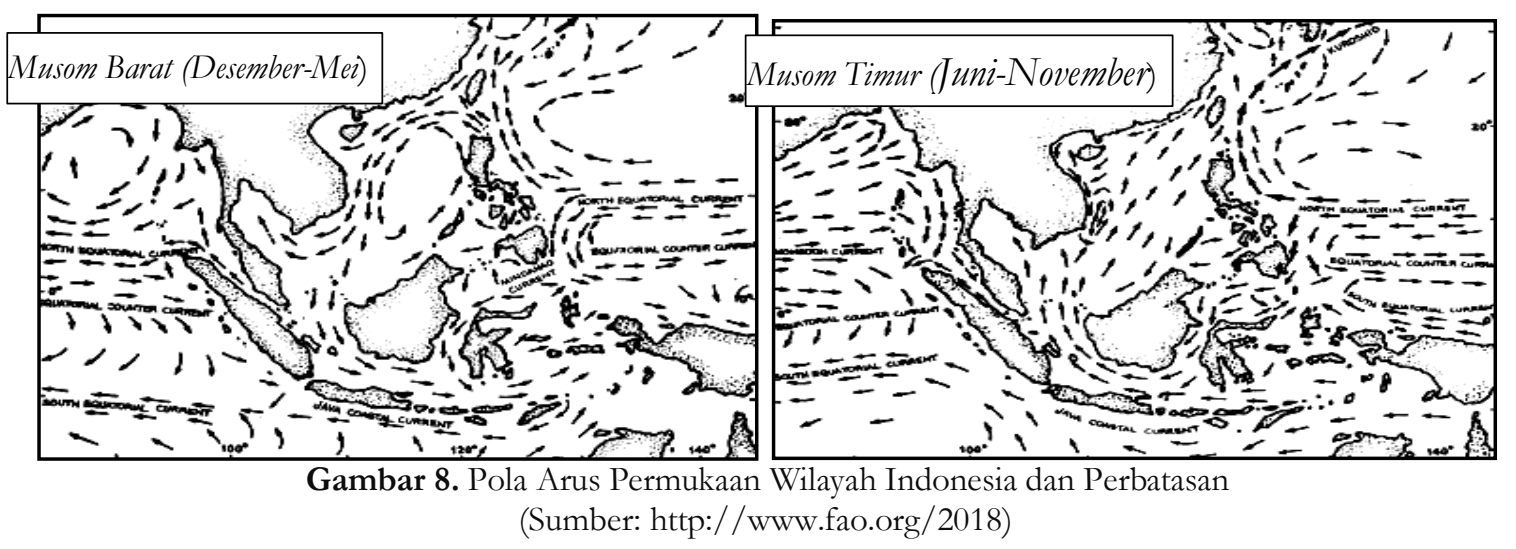

Berbicara mengenai abrasi pantai tentu tidak bisa lepas dari aktivitas manusia yang tinggal disekitarnya. Terutama aktivitas sosial ekonomi masyarakat setempat. Aktivitas sosial ekonomi di Desa Karimunting, Kecamatan Sungai Raya Kepulauan, Kabupaten Bengkayang Kalimantan Barat seperti aktivitas pendukung kegiatan pariwisata terkonsentrasi pada area pantai. Aktivitas sosial ekonomi kepariwisataan pada pantai Kura-kura ini yaitu aktivitas jual beli seperti warung/rumah makan, aktivitas jasa penginapan, jasa toilet dan kamar mandi dan gazebo-gazebo sebagai tempat santai pengunjung pantai yang terdapat disepanjang Pantai Kura-kura. Aktifitas sosial ekonomi seperti pengelolan area pantai untuk kegiatan pariwisata tanpa mempertimbangan unsur ekologis. Nilai ekonomis yang tinggi dari jasa pariwisata membuat sepanjang pantai kura-kura minim dengan vegetasi penutup lahan. Bangunan-bangunan gazebo yang berjajar di sepanjang pantai membuat tidak ada lagi space atau ruang untuk vegetasi pentup lahan seperti tanaman bakau dan sejenisnya. Sehingga hal ini akan semakin mempercepat proses terjadinya abrasi pantai. 


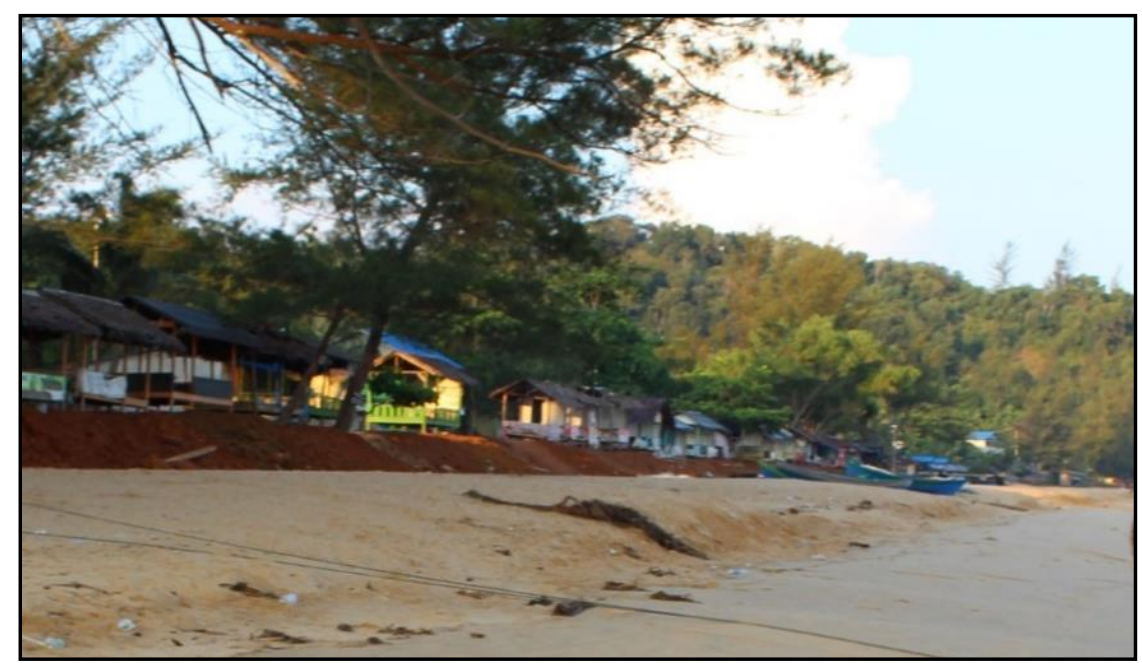

Gambar 9. Aktivitas Sosial Ekonomi Sektor Kepariwisataan di Pantai Kura-kura (Sumber: Data Primer, 2018)

\section{SIMPULAN}

Berdasarkan penelitian yang dilakukan, maka dapat disimpulkan bahwa morfometri perubahan garis pantai Kura-kura Desa Karimunting, Kecamatan Sungai Raya Kepulauan, Kabupaten Bengkayang Kalimantan Barat selama 12 tahun sepanjang 28,4 atau 2,37 meter pertahun. Aspek fisik yang mempengaruhi perubahan garis pantai Kura-kura desa Karimunting yaitu topografi pantai semakin ke selatan semakin menjorok ke arah laut dan menghalangi pergerakan arus laut yang bergerak saling bergantian mengikuti pergerakan angin muson. Sampel profil kemiringan lereng pantai dari dua sampel yang diambil membuktikan bahwa topografi kemiringan lerang pantai semakin ke arah selatan semakin curam. Aspek fisik lain yaitu kurangnya vegetasi penutup lahan yang dapat melindungi tebing pantai sehingga tidak ada akar-akar pohon yang melindungi tebing pantai dari aktivitas abrasi. Aspek sosial yang mempengaruhi perubahan garis pantai yaitu aktivitas sektor kepariwisataan yang ada di pantai Kura-kura. Pendirian bangunan-bangunan semi permanen seperti penginapan, warung dan gazebogazebo tempat bersantai di sekitar area pantai yang tidak memperhatikan kearifan ekologis. Keberadaan bangunan-bangunan yang ada di sekitar pantai mereduksi bahkan mengeliminasi fungsi lahan yang seharusnya sebagai ruang terbuka hijau.

\section{DAFTAR PUSTAKA}

Arifin, A., Awaluddin, M., \& Amarrohman, F. J. (2019). Analisis Pengaruh Perubahan Garis Pantai Terhadap Batas Pengelolaan Wilayah Laut Daerah Provinsi DKI Jakarta. Jurnal Geodesi Undip, 9(1), 156-165.

BPS Bengkayang. (2017). Kabupaten Bengkayang Dalam Angka 2018 (B. Kab_Bengkayang (Ed.); 2018 ${ }^{\text {th }}$ Koperasi Wanita Lestari. https://bengkayangkab.bps.go.id/

Damaywanti, K. (2013). Dampak Abrasi Pantai Terhadap Lingkungan Sosial (Studi Kasus di Desa Bedono, Sayung Demak.

Dinas PU. (2013). Rencana Program Investasi Jangka Menengah (RPIJM) Bidang Cipta Karya Kabupaten Bengkayang. https://sippa.ciptakarya.pu.go.id/

Hoek, F., Muhfizar, M., Simau, S., Suruwaky, A. M., Ulat, M. A., \& Arfah, A. (2015). Potensi sumberdaya udang penaeid di perairan kepulauan aru bagian timur sub wilayah aru dan sekitarnya-III. Jurnal Airaha, 4(1), 18-26.

Muhamad, S. V. (2016). Illegal Fishing di Perairan Indonesia: Permasalahan dan Upaya Penanganannya Secara Bilateral di Kawasan. Jurnal Politica Dinamika Masalah Politik. Dalam Negeri dan Hubungan Internasional, 3(1).

N. Suwarna (GRDC), \& (AGSO), R. P. L. (1993). Peta Geologi Lembar Singkawang, Kalimantan. 
Nurjaya, I. W., \& Atmadipoera, A. S. (2020). Analisis Perubahan Garis Pantai di Wilayah Pantai Barat Kabupaten Tanah Laut Kalimantan Selatan. Jurnal Ilmu dan Teknologi Kelautan Tropis, 12(1), 211222.

Purwaka, T. H. (2015). Tinjauan Hukum Laut Terhadap Wilayah Negara Kesatuan Republik Indonesia. Mimbar Hukum-Fakultas Hukum Universitas Gadjah Mada, 26(3), 355-365.

Putri, N. L. P. T. I., \& Citra, I. P. A. (2018). Strategi Pengelolaan Sumberdaya Pesisir di Desa Pemuteran, Kecamatan Gerokgak Kabupaten Buleleng. Jurnal Pendidikan Geografi Undiksha, 6(1), 154-160.

Raihansyah, T., Setiawan, I., \& Rizwan, T. (2016). Studi Perubahan Garis Pantai di Wilayah Pesisir Perairan Ujung Blang Kecamatan Banda Sakti Lhokseumawe. Jurnal Ilmiah Mahasiswa Kelautan dan Perikanan Unsyiah, 1(1), 46-54.

Richard, R., \& Sunarto, S. (2015). Perubahan Garis Pantai dan Kerusakan Pantai di Kawasan Kepesisiran Kabupaten Tuban Bagian Barat. Jurnal Bumi Indonesia, 4(4), 1-10.

Saksono, H. (2013). Ekonomi Biru: Solusi Pembangunan Daerah Berciri Kepulauan Studi Kasus Kabupaten Kepulauan Anambas. Pusat Penelitian Dan Pengembangan Pemerintaban Umum Dan Kependudukan Badan Penelitian Dan Pengembangan (BPP) - Kementerian Dalam Negeri, 1-12.

Saleh, S. H. (2014). Forecasting of The Electricity Demand in Libya Using Time Series Stochastic Method for Long-Term from 2011-2022. Thesis. UNS (Sebelas Maret University).

Sara, L. (2014). Pengelolaan Wilayah Pesisir, Gagasan Memelihara Aset Wilayah Pesisir dan Solusi Pembangunan Bangsa. Bandung: Alfabeta.

Sembiring, F., Hamdan, \& Mirwandhono, E. (2013). Analisis Morfometrik Kerbau Lumpur (Bubalus Bubalis) Kabupaten Karo Sumatera Utara. Jurnal Peternakan Integratif, 1(2), 134-145.

Sukamto. (2017). Pengelolaan Potensi Laut Indonesia dalam Spirit Ekonomi Islam. Jurnal Ekonomi Islam, 9, 35-62.

Sutanto. (1995). Penginderaan Jauh Jilid 1. Yogyakarta: Gadjah Mada University Press.

Taqwin, N.A., Munawaroh, Q., Sari, D.M., Suryani, E. M., Rahayu, D. A., Listyorini, D. (2014). Studi Morfometrik dan Meristik Ikan Melem Biru (Osteochilus sp.) di Aliran Sungai Ketro, Ponorogo, Jawa Timur. Proceeding Seminar Nasional Biodiversitas V, February 2016.

Wyrtki, K., 1961. Physical Oceanography of the Southeast Asiandinbsp Waters, Naga. Rep. No. 2, p. 1 - 195 Scripps Inst. of Oceanogr., La Jolla, California.

Yani, llbi C., Yoswaty, D., Tanjung, A., Elizal, \& Nasution, S. (2018). Potensi Pengembangan Wisata Bahari Pasir Tiku Kabupaten Agam Provinsi Sumatera Barat. Journal of Chemical Information and Modeling, 53(9), 1689-1699. 